\title{
A Global Optimisation of a Switched Inertance Hydraulic System based on Genetic Algorithm
}

\author{
Min Pan \\ Centre for Power Transmission and Motion Control \\ Department of Mechanical Engineering, University of Bath, Bath, UK \\ E-mail: m.pan@bath.ac.uk
}

\begin{abstract}
The switched inertance hydraulic system (SIHS) is a novel high-bandwidth and energy-efficient device which can adjust or control flow and pressure by a means that does not rely on throttling the flow and dissipation of power. The three-port SIHS usually consists of a high-speed switching valve, an inertance tube and an accumulator. The device can provide an efficient step-up or stepdown of pressure or flow rate by using a digital control technique. The existing analytical models of an SIHS can effectively predict the flow response, pressure loss, system characteristics and efficiency. The optimal switching frequency and ratio of an SIHS can also be accurately estimated by using the analytical models. However, there is no study related to the 'optimal inertance tube', which considers the optimal tube diameter and length corresponding to different system operating frequencies and ratios. In other words, there is inertia and resistance balance of the system. This paper investigates the global optimisation of an SIHS based on genetic algorithm. The energy cost function is proposed, and the optimal solutions are presented. Numerical simulation models are used to validate the results. It provides a general guidance of the SIHS design and its parameter optimisation.
\end{abstract}

Keywords: Switched inertance hydraulic systems; System optimisation; Cost function; Genetic algorithm

\section{Introduction}

The speed or force of a hydraulic system is usually controlled by using hydraulic valves to throttle the flow and therefore reduce the pressure. This approach is simple but inefficient, and it is common for more than $50 \%$ of the input power to be waste in this way.

Digital hydraulic technology was introduced to improve energy efficiency while maintaining good control flexibility and high bandwidth. The switched inertance hydraulic system (SIHS), which performs analogously to an electrical 'switched inductance' transformer, is a promising approach for raising hydraulic systems efficiency. An SIHS makes use of the natural reactive behavior of hydraulic components, and is composed of a high-speed switching valve, small diameter inertance tubes and accumulators.

Different configurations of SIHS were proposed initially by Brown [1, 2], where three-port valves and four-port valves were applied as the switching element with one and two inertance tubes, respectively. The advantages and challenges of switched hydraulic systems have been studied relative to conventional valve controlled systems. High bandwidth and great efficiency are the two main advantages [2, 3]. With a high switching frequency, the SIHS has a wider bandwidth than the conventional orifice-metered system. An ideal SIHS could perform $100 \%$ efficiency with the neglecting of power losses due to friction and leakage.

Figure 1 shows the two basic configurations of SIHSs, a flow booster and a pressure booster, which are configured by reversing the inlet and outlet connections in a three-port SIHS [3]. To achieve bi-direction control ability, the four-port SIHS is introduced, as shown in Figure 2, where two inertance tubes and accumulators were used in the system, providing real four-quadrant operation and seamless changes in direction, such as four-port modulating valves. The threeport and four-port SIHS have been investigated analytically and experimentally at the Centre for Power Transmission and Motion Control at the University of Bath [4-8].

Instead of using a three-port valve, a two-port high-speed onoff valve and a check valve were used to construct an SIHS which is also called Hydraulic Buck-Converter (HBC) [9-10]. The HBC can effectively eliminate the back flow rate as the check valve only allows the flow pass in one director. This is an advantage compared with the structures presented in Figure 1. However, the usage of the check valve introduces new characteristics to the system and a good response speed of the check valve is desired as well. The HBC has been successfully applied in robots and agricultural machines [11, 12]. The high-speed switching valves and $\mathrm{HBC}$ have been 
studies comprehensively in the Institute of Machine Design and Hydraulic Drives at the University of Linz.

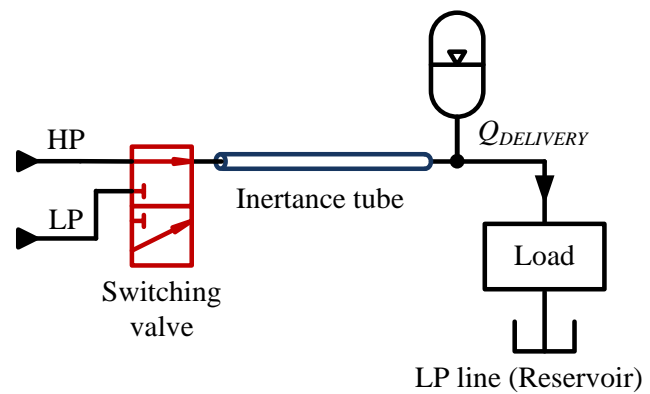

(a)

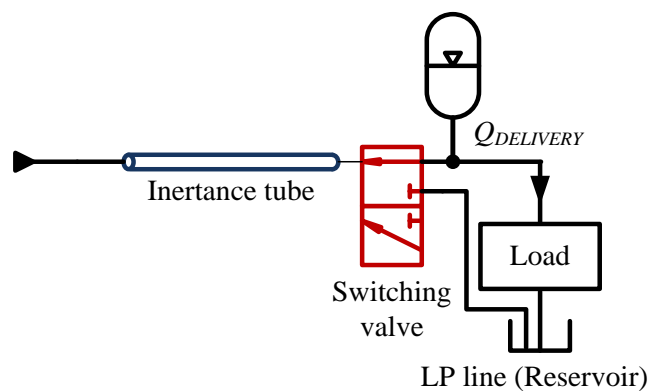

(b)

Figure 1: Schematics of switched inertance hydraulic systems (a). Flow booster configuration;

(b). Pressure booster configuration

It has been concluded and agreed that the transition dynamics of the high-speed switching valve is significant to the overall efficiency $[5,13]$. The 'Soft-Switching' concept is proposed to eliminate the energy losses during the switching transition $[14,15]$. Also, the wave propagation effect along the pipeline has been investigated in $[5,16]$. However, there is no study related to the 'optimal inertance tube', which considers the optimal tube diameter and length corresponding to different system operating frequencies and ratios. In other words, there is inertia and resistance balance of the system, which needs to be addressed.

This paper investigates the global optimisation of an SIHS based on Genetic Algorithm (GA). The energy cost function is proposed and the optimal solutions are presented. First, the enhanced analytical model of a three-port SIHS is reviewed. This is followed by system optimisation based on GA and parameter studies. Simulation investigations on numerical models of an SIHS which employs the optimal operating parameters are presented and followed by the comparisons between the 'optimal configuration' and the conventional SIHS regarding system power consumption.

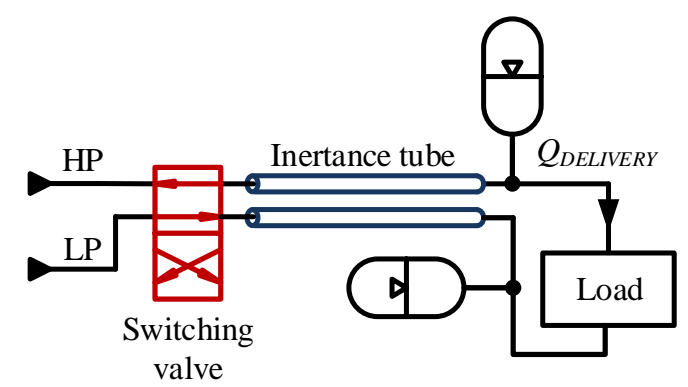

Figure 2: Schematic of a switched inertance hydraulic system in a four-port valve configuration

\section{Enhanced analytical model of SIHS}

An enhanced analytical model of an SIHS including switching transition dynamics, non-linearity and leakage in a three-port switching valve configuration is created and validated in author's previous work [4, 5]. The model is applied for this study. It also has been concluded in the previous work that the optimal switching frequency and ratio are highly dependent on the wave propagation in the pipeline, and that the optimal switching cycle equals to the wave propagation time divided by the switching ratio $\alpha$ or $(1-\alpha)$ with an ideal instantaneous switching.

$$
T= \begin{cases}\frac{t_{\text {wave }}}{\alpha} & 0 \leq \alpha \leq 0.5 \\ \frac{t_{\text {wave }}}{1-\alpha} & 0.5<\alpha \leq 1\end{cases}
$$

where $t_{\text {wave }}$ is the wave propagation time $t_{\text {wave }}=2 L / c, \mathrm{c}$ is the speed of sound and $L$ is the tube length [8].

With required switching ratios (determined by load pressure), the optimal switching frequencies can be estimated and the optimal operating curve can be achieved, as shown in figure 3 , where the SIHS is operating with lowest power loss. $f_{1}, f_{2}$ and $f_{3}$ are the optimal switching frequencies for the switching ratios $\alpha_{1}, 0.5$ and $\alpha_{2}$.

The power loss of an SIHS is given by [4]:

$$
P_{\text {loss }}=\left(p_{H}-p_{L}\right) q_{\text {loss }}+q_{m}^{2} R_{t}
$$

where $p_{\mathrm{H}}$ and $p_{\mathrm{L}}$ are high and low supply pressures, $q_{\text {loss }}$ is the flow loss of the system $[4,5], q_{\mathrm{m}}$ is the average delivery flow rate and $R_{\mathrm{t}}$ is the overall system resistance.

The flow loss based on the lumped parameter model in timedomain is given by [4]:

$$
q_{\text {loss }}=\frac{\tau\left(e^{\frac{\alpha T}{\tau}}-e^{\frac{T}{\tau}}+e^{\frac{T-\alpha T}{\tau}}-1\right)+\alpha T(1-\alpha)\left(e^{\frac{T}{\tau}}-1\right)}{\left(e^{\frac{T}{\tau}}-1\right) T R_{t}}\left(p_{H}-p_{L}\right)
$$

where $\alpha$ is the switching ratio, $T$ is the switching cycle, $\tau$ is the time constant $\tau=I / R_{\mathrm{t}}$;

$I$ is the inertance of the tube: 


$$
I=\frac{\rho L}{A}
$$

The flow loss based on the distributed parameter model in frequency-domain is given by [4]:

$$
q_{\text {loss }}=-2 \sum_{n=0}^{\infty} \operatorname{Re}\left[\frac{Q_{n}}{2 \pi n j}\left(1-e^{j n 2 \pi \alpha}\right)\right]
$$

where $Q_{\mathrm{n}}$ are the Fourier coefficients of the inlet flow rate of the inertance tube,

$$
Q_{n}=\frac{p_{H}\left(1-e^{-j 2 \pi n \alpha}\right)+p_{L}\left(e^{-j n 2 \pi \alpha}-e^{-j n 2 \pi}\right)}{2 \pi n j\left(j Z_{0} \xi \tan \left(\frac{\omega L \xi}{c}\right)+R_{v}\right)}
$$

$Z_{0}$ is the pipe characteristic impedance,

$$
Z_{0}=\frac{\rho c}{A}
$$

$\xi$ is the viscous wave correction factor [17],

$$
\xi=\left(1-\frac{2}{z} \frac{J_{1}(z)}{J_{0}(z)}\right)^{-\frac{1}{2}} \text { and } z=j r \sqrt{\frac{j \omega}{v}}
$$

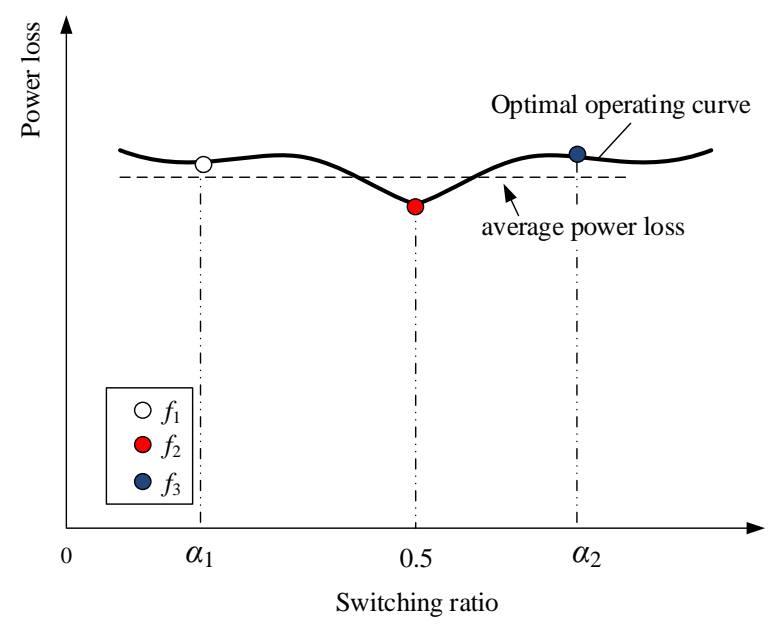

Figure 3: Optimal operating curve

\section{Genetic algorithm and SIHS optimisation}

An algorithm for solving optimisation problems is generally a sequence of computational steps which asymptotically converge to an optimal solution. Most classical optimisation methods generate a deterministic sequence of computation based on the gradient or higher order derivatives of the objective function. The methods are applied to a single point in the search space. The point is then improved along the deepest descending direction gradually through iterations. This point-to-point approach embraces the danger of failing in local optima. Genetic algorithm (GA) performs a multidirectional search by maintaining a set of potential solutions. The usual form of GA is described by Goldberg [18]. GAs are stochastic search algorithms based on the mechanism of natural selection and natural genetics. Figure 4 shows the flow chart of GA, and $P(\mathrm{t})$ and $C(\mathrm{t})$ are parents and off- spring in current generation $t$, respectively and the general implementation structure of GA is described as follows [18].

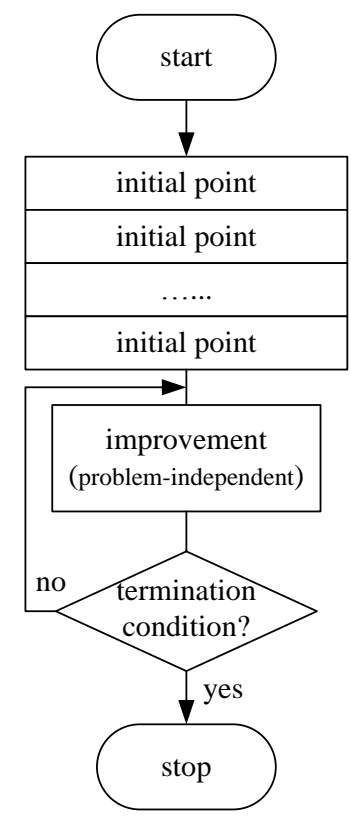

Figure 4: Flow chart of Genetic Algorithm [18]

procedure: basic GA

input: problem data, GA parameters

output: the best solution

begin

$t \leftarrow 0$

initialize $\mathrm{P}(\mathrm{t})$ by encoding routine;

evaluate $\mathrm{P}(\mathrm{t})$ by encoding routine;

while (not terminating condition) do

create $\mathrm{C}(\mathrm{t})$ from $\mathrm{P}(\mathrm{t})$ by crossover routine;

create $C(t)$ from $P(t)$ by mutation routine;

evaluate $\mathrm{C}(\mathrm{t})$ by decoding routine;

routine; select $\mathrm{P}(\mathrm{t}+1)$ from $\mathrm{P}(\mathrm{t})$ and $\mathrm{C}(\mathrm{t})$ by selection

$t \leftarrow t+1$

end

output the best solution

end

The optimal operating curve of an SIHS shown in Figure 3 is symmetric with an instantaneous switching transition [4]. The optimisation process can be described as follows and the flow chart is shown in figure 5 .

1. Initial $\alpha_{1}$ and $\alpha_{2}$ to define the considered optimisation boundary; this is determined by the load system.

2. Determine the constraints of the diameter $d$ and length $l$ of the inertance tube;

3. Calculate the optimal switching frequencies of the highspeed switching valve in terms of different switching ratios using equation (1).

4. Define the power loss evaluation function based on the basic or enhanced analytical model of an SIHS;

5. Apply GA to find the optimal solutions ( $d$ and $l$ );

6. Output the best solution of the diameter and length. 
The constraints of the tube length and diameter are determined in terms of valve performance beforehand. For example, the length of the inertance tube is restricted by the maximum switching frequency of the high-speed switching valve. The maximum switching frequency required would be the optimal switching frequency corresponding to the switching ratio of 0.5 . An evaluation function (cost function) of system power loss is defined as:

$$
\begin{gathered}
F(\boldsymbol{\alpha}, \mathbf{f}, d, l)=\frac{1}{n} \sum_{i=1}^{n} P_{i}^{2} \\
\mathbf{P}(\boldsymbol{\alpha}, \mathbf{f}, d, l)=\left(p_{H}-p_{L}\right) \mathbf{q}_{\text {loss }}+q_{m}^{2} R_{t} \\
n=\frac{\alpha_{1}-\alpha_{2}}{\Delta \alpha}+1
\end{gathered}
$$

where $i$ is the index number, $\alpha_{1}$ and $\alpha_{2}$ are switching ratios, $\Delta \alpha$ is the step of the switching ratio and $d$ is the tube diameter and $l$ is the tube length.

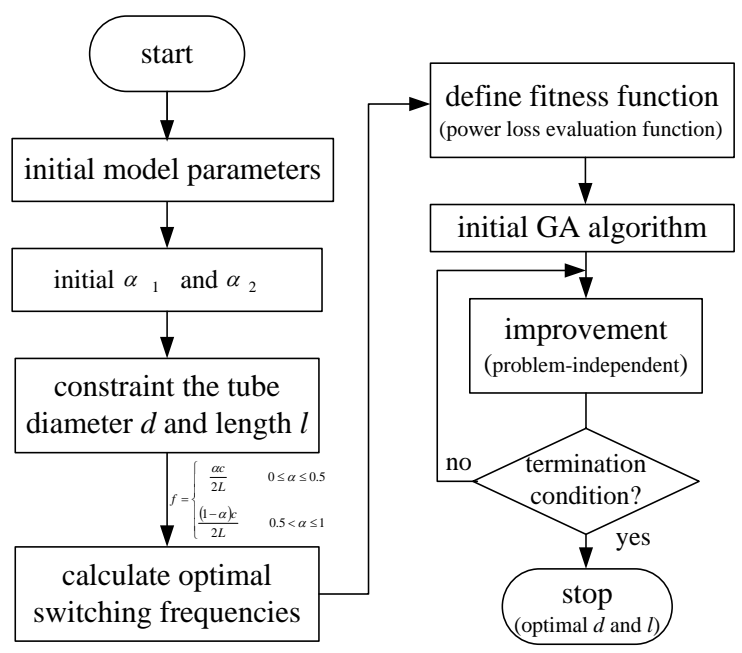

Figure 5: Flow chart of SIHS optimisation

\section{Optimization studies}

Different optimisation boundaries $\left(\alpha_{1}\right.$ and $\alpha_{2}, 0.1 \leq \alpha_{1} \leq 0.9$ $0.1 \leq \alpha_{2} \leq 0.9$ ) are applied for the optimisation study. The same delivery flow rate $7 \mathrm{~L} / \mathrm{min}$ is assumed for different switching ratios. The constraint of the tube length is from 0.6 $\mathrm{m}$ to $2 \mathrm{~m}$; whilst constraint of the tube diameter is from $6 \mathrm{~mm}$ and $20 \mathrm{~mm}$. Longer tube length $(>2 \mathrm{~m}$ ) or smaller tube diameter $(<6 \mathrm{~mm})$ would cause high resistance; whilst shorter tube length $(<0.6 \mathrm{~m})$ and bigger tube diameter $(>20$ $\mathrm{mm}$ ) may not be able to provide enough inertia. Three optimisation cases were investigated, and the parameters used in optimisation are listed in table 1.

Table 1 Parameters in optimisation of an SIHS

\begin{tabular}{ll}
\hline Density $\rho$ & $870 \mathrm{~kg} / \mathrm{m}^{3}$ \\
Viscosity $v$ & $32 \mathrm{cSt}$ \\
High supply pressure $p_{H}$ & $100 \mathrm{bar}$ \\
Low supply pressure $p_{L}$ & $50 \mathrm{bar}$ \\
Delivery flow rate $q_{\mathrm{m}}$ & $7 \mathrm{~L} / \mathrm{min}$ \\
Switching valve orifice area $A$ & $0.337 \mathrm{~cm}^{2}$ \\
\hline
\end{tabular}

\begin{tabular}{ll}
\hline Switching frequency $f$ & Optimal \\
Speed of sound $c$ & $1350 \mathrm{~m} / \mathrm{s}$ \\
Number of spectral components & 400 \\
\hline
\end{tabular}

\subsection{Case 1: $\alpha_{1}<\alpha_{2}<0.5$}

When the system operates with the switching ratio less than 0.5 , the maximum delivery pressure is explicitly less than 75 bar (switching ratio $=0.5$ ). Assuming the operating pressure required in this case is range from 55 bar to 70 bar, the switching ratio is corresponding from 0.1 to 0.4 , as shown in Figure 6 (a) Case 1. Figure 7 (a) shows the fitness evaluation of system power loss. The best $F(x) 2456 \mathrm{~W}^{2}$ was found with the tube diameter of $0.94 \mathrm{~cm}$ and the length of $0.6 \mathrm{~m}$.

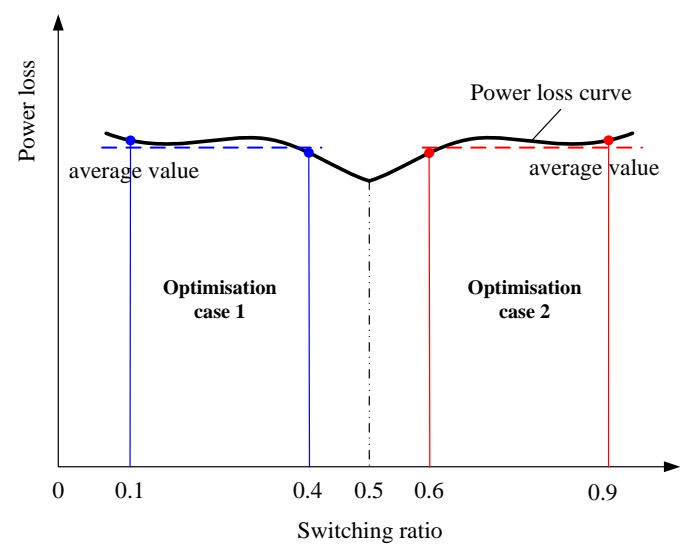

(a)

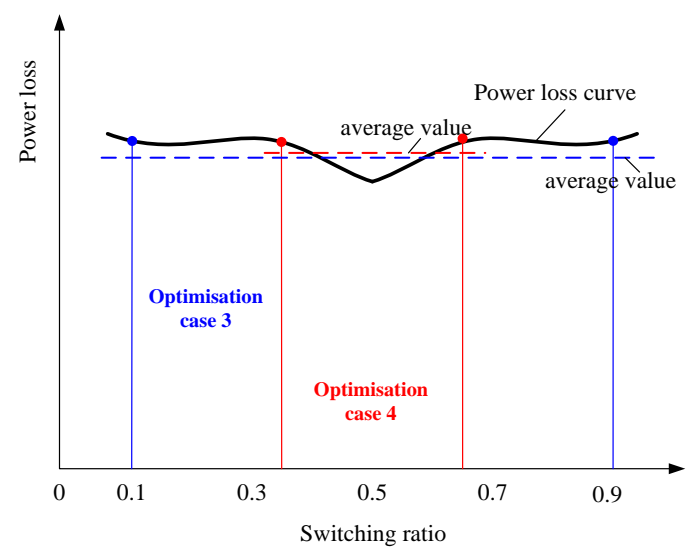

(b)

Figure 6: Different optimisation boundaries

\subsection{Case 2: $0.5<\alpha_{1}<\alpha_{2}$}

The boundary is set with the switching ratio ranging from 0.6 to 0.9, as shown in Figure 6 (a) Case 2. The SIHS can provide the delivery pressure from 80 bar to 95 bar theoretically. The best $F(x) 2499 \mathrm{~W}^{2}$ was found with the tube diameter of 0.94 $\mathrm{cm}$ and the length of $0.61 \mathrm{~m}$. The optimal solution with this boundary condition is very similar to Case 1 as the possible reason of the symmetrical optimisation area. Figure 7 (b) shows the fitness evaluation of system power loss.

4.3 Case 3: $\alpha_{1}<0.5<\alpha_{2}$ 
Considering a wider boundary condition, the switching ratio is set from 0.1 to 0.9, as shown in Figure 6 (b) Case 3. The best $F(x) 2424.8 \mathrm{~W}^{2}$ was found with the tube diameter of 0.95 $\mathrm{cm}$ and the length of $0.62 \mathrm{~m}$. Figure 7 (c) shows the fitness evaluation of system power loss. Simply narrow the boundary down of the switching ratio from 0.3 to 0.7 , the best $F(x)$ $2123.6 \mathrm{~W}^{2}$ was obtained with the tube diameter of $1.01 \mathrm{~cm}$ and the length of $0.63 \mathrm{~m}$. The fitness evaluation of system power loss was shown in Figure 7 (d).
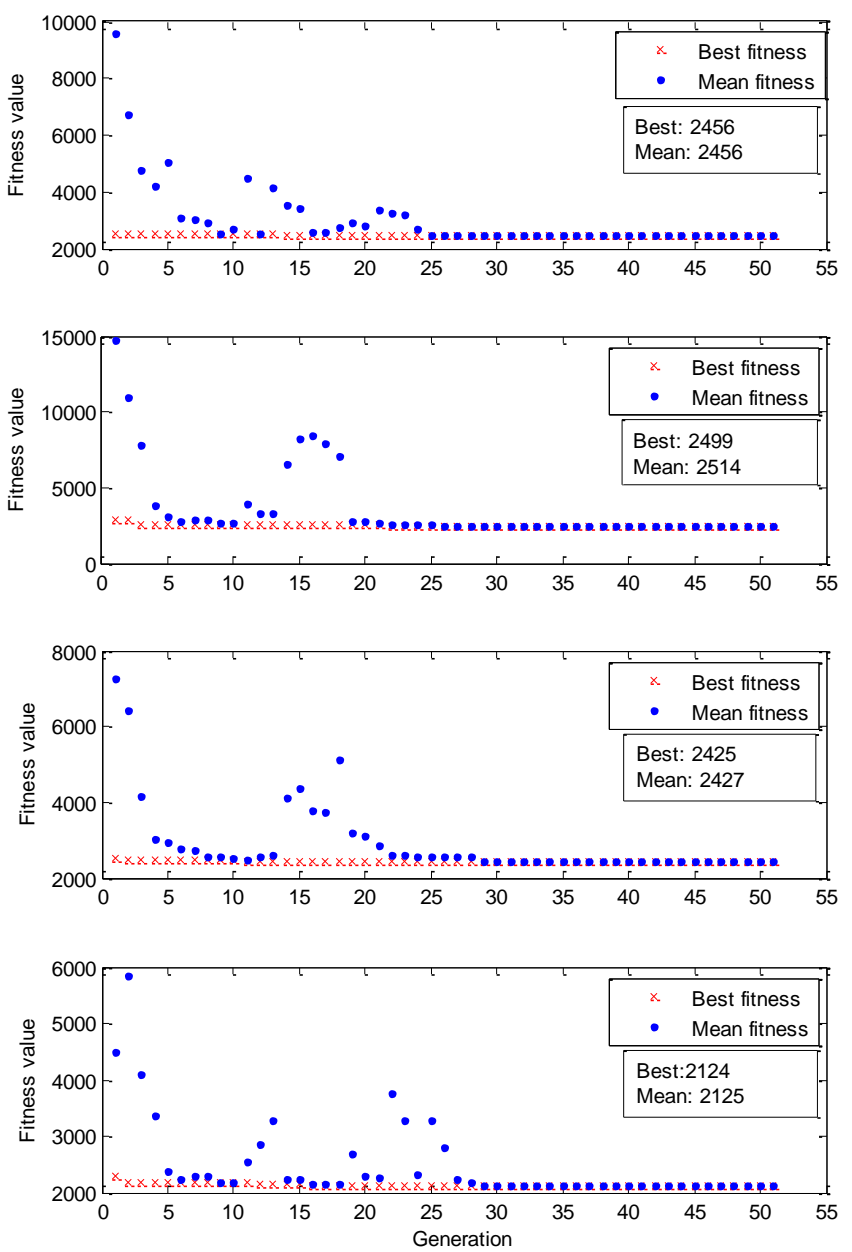

Figure 7: Fitness value against generation using $G A(a)$. $0.1 \leq \alpha \leq 0.4$ (case 1 ); (b). $0.6 \leq \alpha \leq 0.9$ (case 2 ); (c). $0.1 \leq \alpha \leq 0.9$ (case 3); (d). $0.3 \leq \alpha \leq 0.7$ (case 4 )

With three cases presented above, it can be concluded that the optimal tube length is $0.62 \mathrm{~m}$ and the diameter is $0.95 \mathrm{~cm}$ for a three-port SIHS. This means the high-speed switching valve needs to be able to switch with the maximum switching frequency of $544 \mathrm{~Hz}$, which seems to be achievable with the reference of previous work [2]. The compromise can be also made by constraining the tube length further. For example, with a high-speed switching valve with a maximum switching frequency of $100 \mathrm{~Hz}$, the tube should at least be $3.375 \mathrm{~m}$ in length.

\section{Simulations}

A time domain numerical simulation model was created using MATLAB Simulink to verify the optimisation results. The high-speed switching valve was assumed to switch instantaneously and the switching valve flow was modelled using the standard orifice equation (12).

$$
q_{v}(t)=C_{d} A \sqrt{\frac{2|\Delta p|}{\rho}} \operatorname{sgn} \Delta p
$$

where $\Delta p$ is the pressure difference through the valve, $C_{\mathrm{d}}$ is the discharge coefficient and $A$ is the orifice area.

The Transmission Line Method (TLM) was used to model the inertance tube. The model was developed by Krus et al [19] and modified by Johnston [20] to include unsteady or frequency-dependent friction. This model accurately and efficiently represents wave propagation and laminar friction over a very wide frequency range. A small compressible volume $\left(5 \mathrm{~cm}^{3}\right)$ was included between the high-speed switching valve and the TLM inertance tube model and a large volume $\left(0.02 \mathrm{~m}^{3}\right)$ was included at the load to reduce the pressure pulsation. Parameters used in simulation are listed in table 1.

Figure 8 shows the power loss of an SIHS with a fixed tube diameter of $0.95 \mathrm{~cm}$ and different tube lengths. It illustrates the length of $0.62 \mathrm{~m}$ gives the lowest power loss below 25 Watt which is nearly half of using a $3 \mathrm{~m}$ tube and the same diameter tube.

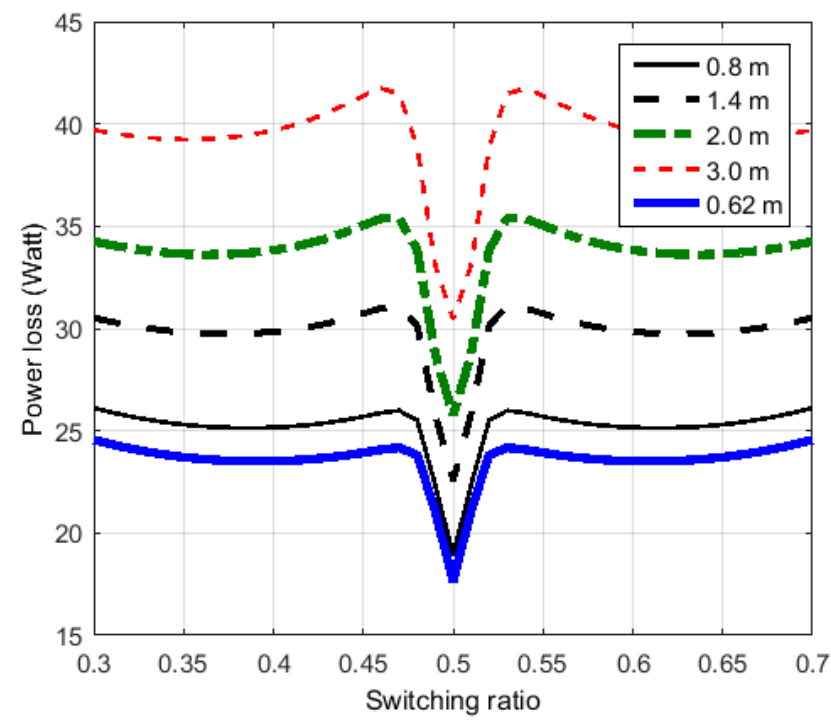

Figure 8: Power loss of an SIHS with different tube length $(0.3<$ switching ratio $<0.7$; tube diameter $=0.95 \mathrm{~m})$

With a fixed tube length of $0.62 \mathrm{~m}$, different tube diameters were used to investigate power consumption, as shown in Figure 9, where $9.5 \mathrm{~mm}$ diameter tube performed with the lowest power loss about 25 Watt. High energy loss occurred with the tube diameter of $20 \mathrm{~mm}$, which can be caused by less inertia or high flow loss (back flow rate) to the system. 


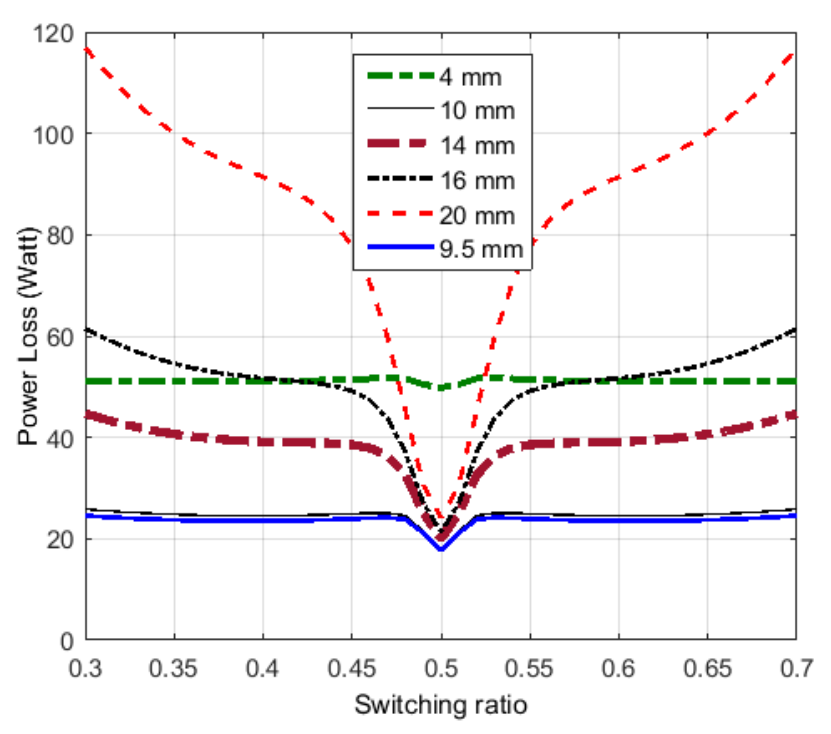

Figure 9: Power loss of an SIHS with different tube diameter $(0.3<$ switching ratio $<0.7$; tube length $=0.62 \mathrm{~m})$

Figure 10 and 11 show the power losses with the switching ratio ranging from 0.6 to 0.9 , which suits the applications requiring high operating pressures. The result confirms that the optimal tube has the length of $0.62 \mathrm{~m}$ and the diameter of $9.5 \mathrm{~mm}$. The lowest power loss can be achieved by using this combination. Small diameter tube would cause more power loss due to its high resistance. For example, the $4 \mathrm{~mm}$ tube cost twice of energy than the $9.5 \mathrm{~mm}$ tube, as shown in Figure 11.

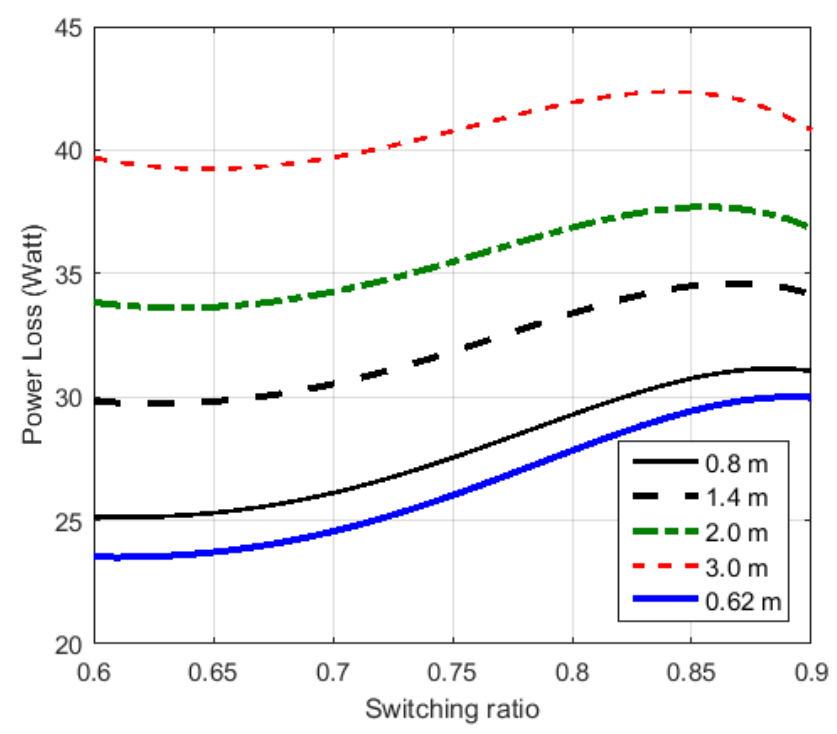

Figure 10: Power loss of an SIHS with different tube length $(0.6<$ switching ratio $<0.9 ;$ tube diameter $=0.95 \mathrm{~m})$

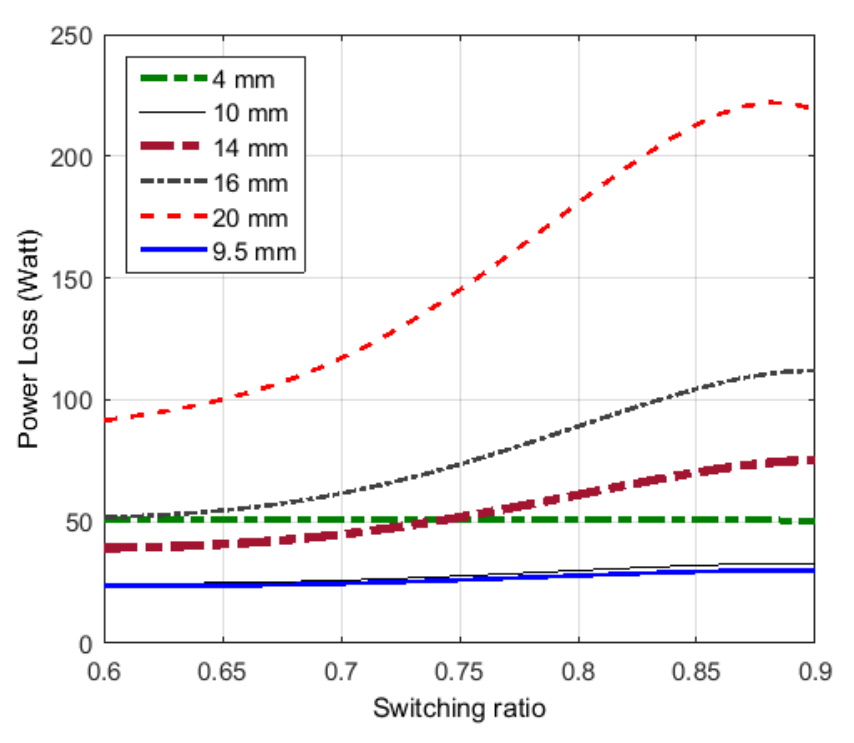

Figure 11: Power loss of an SIHS with different tube diameter $(0.6<$ switching ratio $<0.9$; tube length $=0.62 \mathrm{~m})$

\section{Discussion}

The proposed optimization approach based on GA can effectively predict the optimal parameters for an SIHS, and has been validated through simulation. Some future work needs to be undertaken. The characteristics of the optimal system need to be investigated and validated through experimental work. The effect of the speed of sound needs to be investigated in depth with the optimal tube length and diameter. The author expects the varying of the speed of sound would result in an inaccuracy of the optimisation. The high-speed rotary valve developed at the Centre for Power Transmission and Motion Control at the University of Bath has been operated with the maximum switching frequency of $200 \mathrm{~Hz}$. The noise becomes significant when operates the valve beyond this frequency. Although some noise attenuation research has been carried out at the Centre [21], it seems the experiments will be carried out below $200 \mathrm{~Hz}$, which will constrain the tube length no shorter than $1.7 \mathrm{~m}$.

\section{Conclusions}

The SIHS is a novel high-bandwidth and energy-efficient device which can adjust or control flow and pressure by using Pulse Width Modulation signal. The three-port SIHS in an optimal configuration has been shown to be very energyefficient. The optimisation study concluded that the best tube length is $0.62 \mathrm{~m}$ and the diameter is $0.95 \mathrm{~cm}$. A high-speed switching valve is required and the maximum switching frequency of the valve could constrain the boundary of considered parameters. Although duty cycle dependent, the examples given show power loss remained lowest with the optimal parameters. This study provides a general guidance for the design of an SIHS and the technique for parameter optimisation. 


\section{References}

[1] Brown, F.T., Switched reactance hydraulics: a new way to control fluid power, Proceedings of the National Conference on Fluid Power, Chicago, pp.25-34, 1987.

[2] Brown,F.T., A hydraulic rotary switched inertance servo-transformer, Transactions ASME Journal of Dynamic Systems, Measurement, and Control, vol. 110, pp.144-150, 1988.

[3] Johnston, D.N., A switched inertance device for efficient control of pressure and flow, Proceedings of the Bath/ASME Fluid Power and Motion Control Symposium, Hollywood, USA, pp.1-8. 2009.

[4] Pan, M., Johnston, D.N., Plummer, A., Kudzma, S. and Hillis, A., Theoretical and experimental studies of a switched inertance hydraulic system. Proceedings of the Institution of Mechanical Engineers, Part I: Journal of Systems and Control Engineering, Vol. 228 (1), pp. 1225,2014

[5] Pan, M., Johnston, D.N., Plummer, A., Kudzma, S. and Hillis, A., Theoretical and experimental studies of a switched inertance hydraulic system including switching transition dynamics, non-linearity and leakage. Proceedings of the Institution of Mechanical Engineers, Part I: Journal of Systems and Control Engineering, vol. 228 (10), pp. 802-815, 2014.

[6] Pan, M., Johnston, D.N., Robertson, J., Plummer, A., Hillis, A. and Yang, H., Experimental investigation of a switched inertance hydraulic system with a high-speed rotary valve. Transactions ASME Journal of Dynamic Systems, Measurement and Control, 137 (12), 121003. 2015.

[7] Johnston, D.N., Pan, M., Plummer, A., Hillis, A. and Yang, H., Theoretical studies of a switched inertance hydraulic system in a four-port valve configuration. In: The Seventh Workshop on Digital Fluid Power, Linz, Austria, 2015.

[8] Pan, M. Plummer, A. El Agha, A. Theoretical and Experimental Studies of a Switched Inertance Hydraulic System in a Four-Port High-Speed Switching Valve Configuration . Preprints 2017, 2017040177 (DOI: 10.20944/preprints201704.0177.v1). Submitted to Energies.

[9] Scheidl, R., B. Manhartsgruber, H. Kogler, B. Winkler, and M. Mairhofer. The hydraulic buck converterconcept and experimental results. In Proceedings of the Sixth International Conference on Fluid Power, Dresden, Germany, 2008.

[10] Kogler, H. and Scheidl, R., Two basic concepts of hydraulic switching converters. In The First Workshop on Digital Fluid Power, Tampere, Finland. Oct, 2008.
[11] Kogler, H., Scheidl, R., Ehrentraut, M., Guglielmino, E., Semini, C., and Caldwell, D. G., A compact hydraulic switching converter for robotic applications, Fluid Power and Motion Control, Bath, pp. 55-66, 2010.

[12] Scheidl, R., Garstenauer, M., and Manhartsgruber, B., Switching type control of hydraulic drives-A promising perspective for advanced actuation in agricultural machinery, SAE Technical Paper No. 2000-01-2559. 2009.

[13] Van de Ven, J. D., On fluid compressibility in switchmode hydraulic circuits-Part I: modeling and analysis, ASME J. Dyn. Syst. Meas. Control, 135(2), p. 021013, 2013.

[14] Rannow, M.B. and Li, P.Y., Soft switching approach to reducing transition losses in an on/off hydraulic valve. Journal of dynamic systems, measurement, and control, 134(6), p.064501. 2012.

[15] Yudell, A.C. and Van de Ven, J.D., Soft Switching in Switched Inertance Hydraulic Circuits. In BATH/ASME Symposium on Fluid Power and Motion Control (pp. V001T01A040-V001T01A040). American Society of Mechanical Engineers. 2016.

[16] Kogler, H., Scheidl, R. and Schmidt, B.H., Analysis of wave propagation effects in transmission lines due to digital valve switching. In ASME/BATH 2015 Symposium on Fluid Power and Motion Control (pp. V001T01A057-V001T01A057). American Society of Mechanical Engineers. October 2015.

[17] Stecki, JS, Davis, D., Fluid transmission lines distributed parameter models part 1: a review of the state of the art. Proceedings of the Institution of Mechanical Engineers, Part A: J Power and Energy; 200: 215 - 228, 1986.

[18] Goldberg, D.E., Holland, J.H., Genetic algorithms and machine learning. Machine learning, 3(2), pp.95-99. 1988.

[19] Krus, P., Weddfelt, K., Palmberg, JO., Fast pipeline models for simulation of hydraulic system. Transactions ASME Journal of Dynamic Systems, Measurement and Control, 116: 132-136. 1994.

[20] Johnston DN. The transmission line method for modelling laminar flow of liquid in pipelines. Proceedings of the Institution of Mechanical Engineers, Part I: Journal of Systems and Control Engineering; 226:586-597. 2012.

[21] Pan, M., Adaptive control of a piezoelectric valve for fluid-borne noise reduction in a hydraulic buck converter. Transactions ASME Journal of Dynamic Systems, Measurement and Control. DOI: 10.1115/1.4035613. 2017. 